\title{
Development and Validation of a GC-MS Method for the Simultaneous Determination of Acetochlor, Fluorochloridone, and Pendimethalin in a Herbicide Emulsifiable Concentrate Formulation
}

\author{
Dandan Wang ${ }^{1}$ and Shengde $\mathrm{Wu}^{2 *}$ \\ 'Analysis and Test Center, Yancheng Institute of Technology, 211 Jianjun East Road, Jiangsu Yancheng 224051, P.R. China \\ ${ }^{2}$ Yancheng Products Quality Supervision and Inspection Institute, 2 Weiqi Road, Jiangsu Yancheng 224056, P.R. China
}

Received: 05 Sep 2019; accepted: 20 Oct 2019

\begin{abstract}
This paper describes a rapid method to simultaneously determine acetochlor, fluorochloridone and pendimethalin present in a herbicide emulsifiable concentrate (EC) formulation using gas chromatography-mass spectrometry (GC-MS). Selected ion monitoring mode was performed to increase the sensitivity, with dibutyl phthalate as an internal standard. The method was validated with respect to linearity, accuracy, precision, and stability. Chromatographic separation was carried out on a TG-5 MS column $(30 \mathrm{~m} \times 0.25 \mathrm{~mm} \times 0.25 \mu \mathrm{m})$ with helium as the carrier gas at a flow rate of $1.0 \mathrm{~mL} / \mathrm{min}$. Calibration curves were linear over $2.0-20.0 \mu \mathrm{g} / \mathrm{mL}$ for each analyte, and the limit of quantification was below $20 \mathrm{ng} / \mathrm{mL}$. Good performance in terms of recovery ranging from $94.5 \%$ to $102.5 \%$ at 3 concentration levels proved excellent accuracy. The intra- and inter-day relative standard deviations for 6 replicate measurements were always less than $5 \%$. The developed method is simple and efficient for the routine determination of the ternary mixtures in a compound herbicide EC formulation product.
\end{abstract}

Keywords: acetochlor, fluorochloridone, pendimethalin, GC-MS, internal standard method

\section{Introduction}

Acetochlor (AC) is chemically designated as 2-chloro- $N$ (ethoxymethyl)- $N$-(2-ethyl-6-methylphenyl)acetamide

(Figure 1A). It is a chloroacetanilide-type herbicide. Pendimethalin (PDM) is chemically designated as 3,4-dimethyl-2,6dinitro-N-(pentan-3-yl)benzenamine (Figure 1B). It is a dinitroaniline-group herbicide. Both $\mathrm{AC}$ and PDM were used for control of annual grasses and broadleaf weeds in crops, such as corn, soybean, peanut, cotton, etc. [1]. Fluorochloridone (FCD) is chemically designated as 3-chloro-4-(chloromethyl)1-[3-(trifluoromethyl)phenyl]-2-pyrrolidinone (Figure 1C). It is a pyrrolidone-family herbicide for the control of many broadleaf weeds and annual grasses in cereal, sunflower, potato, and garlic fields [2-5].

Due to certain differences in weeding mechanism between $\mathrm{AC}, \mathrm{PDM}$, and FCD, the controlled weed genre of each herbicide varied, whereas a reasonable mix of such weedkillers was favorable to combine the merits of them. Better weed-killing results have been achieved by field trials $[6,7]$. The novel herbicide emulsifiable concentrate (EC) formulation was more powerful than traditional single component.

Several analytical methods have been reported for the analysis of AC, PDM, or FCD, either in isolation or in combination with some other components mainly in the research of herbicide residue samples. Many analytical methods were reported to analyze AC including high-performance liquid chromatography (HPLC) [8], liquid chromatography-electrospray ionization mass spectrometry (LC-ESI-MS) [9, 10], gas chromatography with electron capture detection (GC-ECD) $[1,11]$, gas chromatography-mass spectrometry (GC-MS) [12], fluorescence polarization immunoassay (FPIA) [13], and near-infrared spectroscopy (NIR) [14]. Similarly, PDM was analyzed by different methods consisted of GC-MS [15],

*Author for correspondence: shengdewu@163.com.
HPLC [16], electroanalytical methods [17], differential pulse voltammetry (DPV) [18], and differential pulse polarography (DPP) [19]. Additionally, GC-MS has been applied to determine FCD in agricultural soil [20]. However, no method related to the simultaneous determination of the ternary mixture herbicide has ever been reported in the literature to date.

In the present work, a simple and sensitive GC-MS method to determine AC, PDM, and FCD was established. To improve accuracy and precision, the internal standard (IS) of dibutyl phthalate (DBP) (Figure 1D) was added along with the determined samples. The resulting analytical method was applied to quantify the ternary active compounds in the newly developed herbicide EC formulation.

\section{Experimental}

Chemicals and Reagents. The AC, PDM, and FCD reference standards were purchased from Shanghai Herbicide Research Institute (Shanghai, China). GC-grade DBP was supplied by Aladdin (Shanghai, China). HPLC-grade solvent acetone was supplied by Fisher (Geel, Belgium). The herbicide EC formulation consisting of AC, PDM, and FCD was kindly supplied by a local herbicide enterprise. Helium (purity, 99.999\%) was from Yancheng Guangyuan Gases Co. Ltd. (Yancheng, China).

Instrumentation. GC-MS analysis was performed on a 1310-ISQ GC-MS system (Thermo, USA) equipped with an autosampler (TriPlus RSH). The chromatographic system was integrated via Thermo Xcalibur software version 4.0 system. A TG-5 MS capillary column $(30 \mathrm{~m} \times 0.25 \mathrm{~mm}$ i.d. $\times 0.25 \mu \mathrm{m}$, Thermo) coated with methyl $5 \%$ phenyl siloxane was used for separation. Helium gas $(99.999 \%)$ was used as a carrier gas at a flow rate of $1.0 \mathrm{~mL} / \mathrm{min}$. The injector port maintained at $280{ }^{\circ} \mathrm{C}$ was operated in the split mode with a split ratio of 10:1. The injection volume of each

This is an open-access article distributed under the terms of the Creative Commons Attribution-NonCommercial 4.0 International License (https://creativecommons.org/licenses/by-nc/4.0/), which permits unrestricted use, distribution, and reproduction in any medium for non-commercial purposes, provided the original author and source are credited, a link to the CC License is provided, and changes - if any - are indicated. 
<smiles>CCOCN(C(=O)CCl)c1c(C)cccc1CC</smiles>

(A)

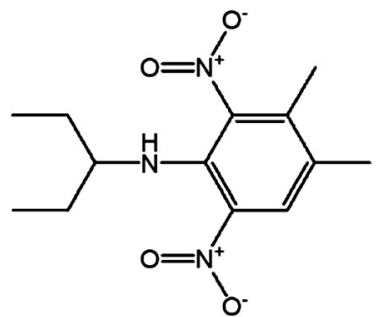

(B)

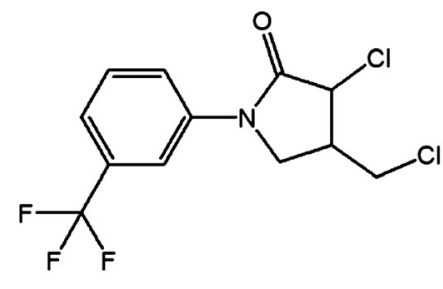

(C)<smiles>CCCCOC(=O)c1ccccc1C(=O)OCCCC</smiles>

(D)

Figure 1. Chemical structures of acetochlor (A), pendimethalin (B), fluorochloridone (C), and dibutyl phthalate (D)

sample was $1.0 \mu \mathrm{L}$. During the run time of $12 \mathrm{~min}$, the oven was held at $200{ }^{\circ} \mathrm{C}$ for $1 \mathrm{~min}$, and then heated to $280{ }^{\circ} \mathrm{C}$ at $10{ }^{\circ} \mathrm{C} / \mathrm{min}$, held for $3 \mathrm{~min}$. MS spectra were detected under the electronic ionization (EI) mode at $70 \mathrm{eV}$. Both the EI source and the transfer line were kept at $250{ }^{\circ} \mathrm{C}$.

To achieve better identification and quantification performance, selected ion monitoring (SIM) mode was used. Considering the selection of highest fragment ion peaks as characteristic ions for monitoring, the MS settings were set as shown in Table 1, in which quantitative ion was $m / z 59,187$, and 252 for AC, FCD, and PDM, respectively. The internal standard curves were calculated by the Processing Setup and Quan Browser module built in the Xcalibur software.

Standard Solutions and Sample Preparation. Standard stock solutions of AC, FCD, and PDM at $1000 \mu \mathrm{g} / \mathrm{mL}$ were prepared separately in a $100 \mathrm{~mL}$ volumetric flask by dissolving $100.0 \mathrm{mg}$ of each drug in acetone diluent. Standard working solutions of mixed $\mathrm{AC}, \mathrm{FCD}$, and PDM at 5 concentration levels $(2.0,4.0,10.0,15.0$, and $20.0 \mu \mathrm{g} / \mathrm{mL})$ were prepared by diluting the above standard stock solutions with acetone. DBP was used as an internal standard (IS) and added to the working standard solutions at a final concentration of $5 \mu \mathrm{g} / \mathrm{mL}$. All solutions were stored at $4{ }^{\circ} \mathrm{C}$ in the dark before injection.

To prepare the sample solutions, approximately 0.1 -g liquid herbicide EC formulation product was accurately weighed into a $50-\mathrm{mL}$ flask before diluting up to the mark with acetone. After shaking up, $1 \mathrm{~mL}$ of the supernatant was taken with a pipette and transferred to another $50-\mathrm{mL}$ flask, and the volume was adjusted to $50 \mathrm{~mL}$ with acetone. The sample solution was filtered through a $0.22-\mu \mathrm{m}$ organic filter before analysis.

\section{Results}

Linearity. The calibration curves were established by injecting ternary mixtures of $\mathrm{AC}, \mathrm{FCD}$, and $\mathrm{PDM}$ at 5 concentration levels ranging from $2-20 \mu \mathrm{g} / \mathrm{mL}$, as well as the internal standard at a constant concentration of $5 \mu \mathrm{g} / \mathrm{mL}$ in

Table 1. MS settings of SIM scan time segments with characteristic ions and quantitative ion of each analyte

\begin{tabular}{lccc}
\hline Analyte & $\begin{array}{c}\text { Time segment } \\
(\mathrm{min})\end{array}$ & $\begin{array}{c}\text { Characteristic ions and } \\
\text { relative abundance (\%) }\end{array}$ & $\begin{array}{c}\text { Quantitative } \\
\text { ion }\end{array}$ \\
\hline Acetochlor & $4.00-4.60$ & $59(100), 146(83.9), 162(69.6)$ & 59 \\
DBP & $4.60-5.20$ & $149(100), 150(8.8), 41(6.7)$ & 149 \\
Fluorochloridone & $5.20-5.55$ & $187(100), 145(91.4), 174(78.3)$ & 187 \\
Pendimethalin & $5.55-12.00$ & $252(100), 162(15.9), 281(14.0)$ & 252 \\
\hline
\end{tabular}

triplicate. The slopes and intercepts within the linear regression equations were summarized in Table 2, where the $Y$-axis of each equation's plot represented the ratio of each analyte's peak area versus the internal standard DBP's peak area, and the $X$-axis was the analyte concentration in $\mu \mathrm{g} / \mathrm{mL}$. The correlation coefficients $\left(R^{2}\right)$ were greater than 0.9947 , showing the excellent linearity of the proposed method.

The limit of detection (LOD) and the limit of quantification (LOQ) of each analyte were determined, giving a signal-tonoise $(\mathrm{S} / \mathrm{N})$ ratio of 3.3 and 10 , respectively.

Limit of detection (LOD) and limit of quantitation (LOQ) were calculated using following equation,

$$
\mathrm{LOD}=\frac{3.3 \sigma}{S} \mathrm{LOQ}=\frac{10 \sigma}{S}
$$

where $\sigma$ is the standard deviation of the $y$-intercept and $S$ is the slope of the corresponding calibration curve.

As it is shown in Table 2, the LOQs were lower than $20 \mathrm{ng} / \mathrm{mL}$.

Accuracy. Recovery experiments were conducted to evaluate the accuracy of the GC-MS method. Three concentration levels of ternary herbicide standards were spiked into pre-analyzed sample solutions and injected in triplicate for accuracy tests. The results were summarized in Table 3. The recovery corresponding to the average detected concentration was $94.5-102.5 \%$, and the percentage relative standard deviation (\%RSD) were less than $10 \%$, confirming the accuracy of the method.

Precision. The \%RSD of the peak area ratio between each analyte and the internal standard obtained from 6 replicate injections of the system suitability solution was used to verify the system precision. As shown in Table 4, quality control

Table 3. Results of recovery experiments

\begin{tabular}{lccrr}
\hline Analyte & $\begin{array}{c}\text { Spiked } \\
\text { concentration } \\
(\mu \mathrm{g} / \mathrm{mL})\end{array}$ & $\begin{array}{c}\text { Detected } \\
\text { concentration } \pm \mathrm{SD} \\
(\mu \mathrm{g} / \mathrm{mL})\end{array}$ & $\begin{array}{c}\text { RSD } \\
(\%)\end{array}$ & $\begin{array}{c}\text { Recovery } \\
(\%)\end{array}$ \\
\hline Acetochlor & 2.0 & $2.05 \pm 0.15$ & 3.7 & 102.5 \\
& 5.0 & $4.96 \pm 0.23$ & 4.7 & 99.2 \\
Fluorochloridone & 10.0 & $10.02 \pm 0.34$ & 3.4 & 100.2 \\
& 2.0 & $2.04 \pm 0.19$ & 9.6 & 102.0 \\
Pendimethalin & 5.0 & $5.08 \pm 0.21$ & 4.1 & 101.6 \\
& 10.0 & $9.48 \pm 0.65$ & 6.9 & 94.8 \\
& 2.0 & $1.89 \pm 0.16$ & 8.3 & 94.5 \\
& 5.0 & $5.09 \pm 0.16$ & 3.2 & 101.8 \\
& 10.0 & $9.74 \pm 0.44$ & 4.5 & 97.4 \\
\hline
\end{tabular}

Table 2. Calibration curves and sensitivity of the proposed method

\begin{tabular}{lcccccc}
\hline Analyte & Concentration range $(\mu \mathrm{g} / \mathrm{mL})$ & Slope $\pm \mathrm{SD}$ & Intercept $\pm \mathrm{SD}$ & $R^{2}$ & $\mathrm{LOD}(\mathrm{ng} / \mathrm{mL})$ & $\mathrm{LOQ}(\mathrm{ng} / \mathrm{mL})$ \\
\hline Acetochlor & $2.0-20.0$ & $0.0320 \pm 0.0004$ & $-0.0140 \pm 0.0011$ & 0.9986 & 2.5 & 7.6 \\
Fluorochloridone & $2.0-20.0$ & $0.0190 \pm 0.0002$ & $-0.0130 \pm 0.0014$ & 0.9947 & 6.7 \\
Pendimethalin & $2.0-20.0$ & $0.0440 \pm 0.0003$ & $-0.0480 \pm 0.0045$ & 0.9965 & 5.9 & 18 \\
\hline
\end{tabular}


Table 4. Results of intra-day and inter-day precision of the method $(n=6)$

\begin{tabular}{lccccc}
\hline Analyte & \multicolumn{2}{c}{$\begin{array}{c}\text { Intra-day precision, } \\
\text { RSD (\%) }\end{array}$} & & \multicolumn{2}{c}{$\begin{array}{c}\text { Inter-day precision, } \\
\text { RSD (\%) }\end{array}$} \\
\cline { 2 - 3 } \cline { 5 - 6 } & $4.0 \mu \mathrm{g} / \mathrm{mL}$ & $15.0 \mu \mathrm{g} / \mathrm{mL}$ & & $4.0 \mu \mathrm{g} / \mathrm{mL}$ & $15.0 \mu \mathrm{g} / \mathrm{mL}$ \\
\hline Acetochlor & 2.9 & 2.3 & & 4.0 & 2.7 \\
Fluorochloridone & 3.3 & 3.8 & & 3.5 & 4.1 \\
Pendimethalin & 3.3 & 2.0 & & 3.7 & 3.3 \\
\hline
\end{tabular}

standards at relatively low and high concentration were analyzed, either intra-day or inter-day for repeatability test, and the results were found within the acceptable limits $(\% \mathrm{RSD}<5 \%)$.

Stability. The stability of the working solutions of the ternary herbicide standards was tested for several consecutive days, and it was found to be stable for at least 4 days at room temperature. No appreciable changes were observed during the procedure.

Analysis of Herbicide EC Formulation. Upon the detected concentrations performed by GC-MS with the established method, the content ( $\%$ mass) of AC, FCD, and PDM found in 2 different herbicide EC formulations was recalculated based on the dilution factor and is shown in Table 5. In spite of the varied formulations, the content sequence of analytes was as follows: acetochlor > pendimethalin $>$ fluorochloridone.

Table 5. Contents of acetochlor, fluorochloridone, and pendimethalin found in herbicide emulsifiable concentrate formulations

\begin{tabular}{lccc}
\hline Sample & Acetochlor (\%) & Fluorochloridone (\%) & Pendimethalin (\%) \\
\hline S1 & 20.12 & 11.07 & 18.24 \\
S2 & 23.67 & 9.83 & 15.85 \\
\hline
\end{tabular}
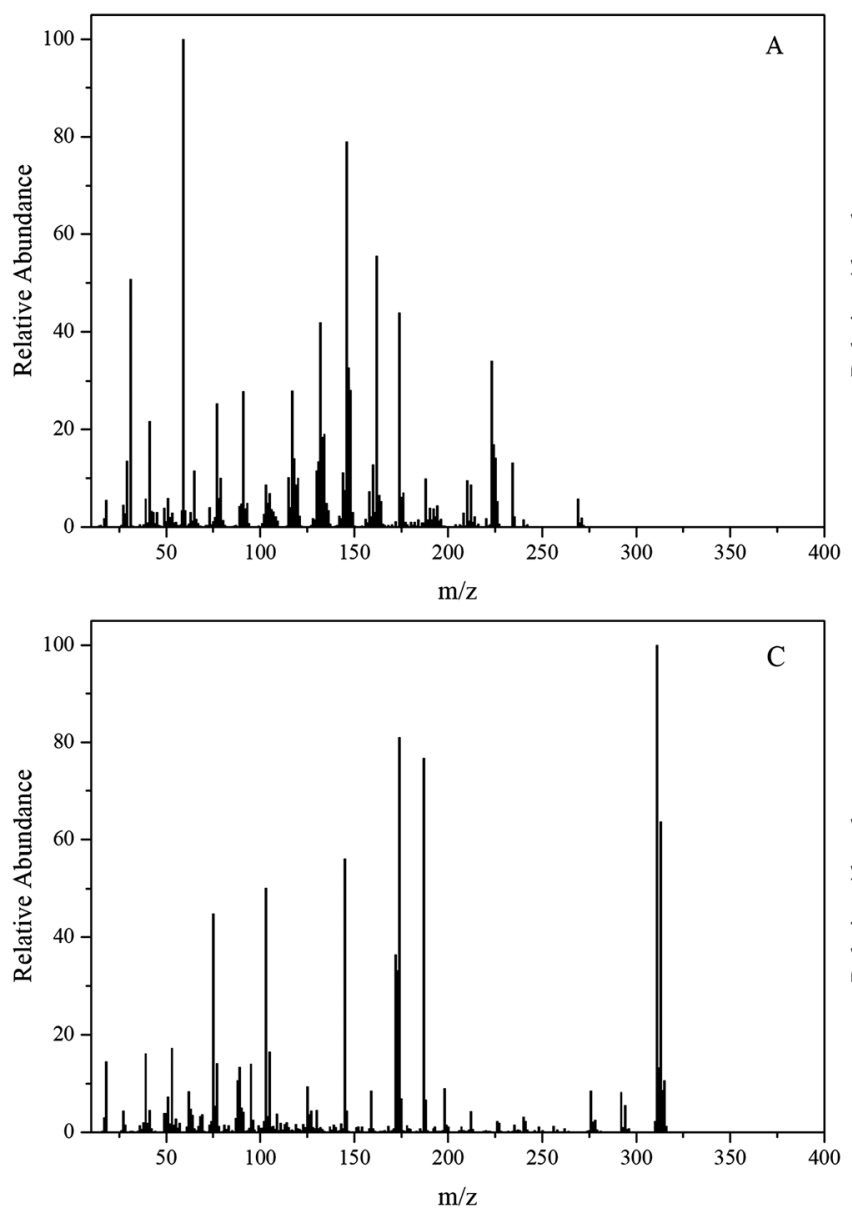

\section{Discussion}

Method Development and Optimization. A satisfactory GC-MS method for ternary mixtures was based on a good chromatographic separation. Thus, different parameters were optimized to obtain an acceptable resolution between the analyte components and a reasonable run time with acceptable recoveries to meet the suitability requirement, mainly including the programmed temperature of the oven. Since the symmetry factor of all the component peaks was among the favorable range of $0.95-1.05$, the separation process was performed on a most frequently used TG-5 MS $(30 \mathrm{~m} \times 0.25 \mathrm{~mm} \times 0.25 \mu \mathrm{m})$ weak-polar capillary column. To get a reasonable run time with efficient resolution, moderate modification of the oven temperature was carried out constantly. As lower initial temperature with lower ramp rates resulted in longer retention times and a bit of peak tailing, the initial oven temperature was finally set at $200{ }^{\circ} \mathrm{C}$, with a moderate ramp rate of $10{ }^{\circ} \mathrm{C} / \mathrm{min}$.

Under the optimized chromatographic conditions and a fullscan MS mode of 10-400 amu, good separation was achieved, and the retention times of $\mathrm{AC}, \mathrm{FCD}, \mathrm{PDM}$, and $\mathrm{DBP}$ were $4.42,5.41,5.65$, and $4.89 \mathrm{~min}$, respectively. The identification of each component was based on the respective MS spectrum as shown in Figure 2. To develop a fast and reliable quantitative GC-MS method, the SIM mode was applied to increase the sensitivity. Based on the retention time of each analyte obtained in full-scan mode, the scan time segment, as well as the characteristic fragment ions of the SIM mode, was set as shown in Table 1, and a typical SIM chromatogram of the mixed standards was shown in Figure 3. In data processing method, the retention time of $\mathrm{AC}, \mathrm{FCD}, \mathrm{PDM}$, and DBP was
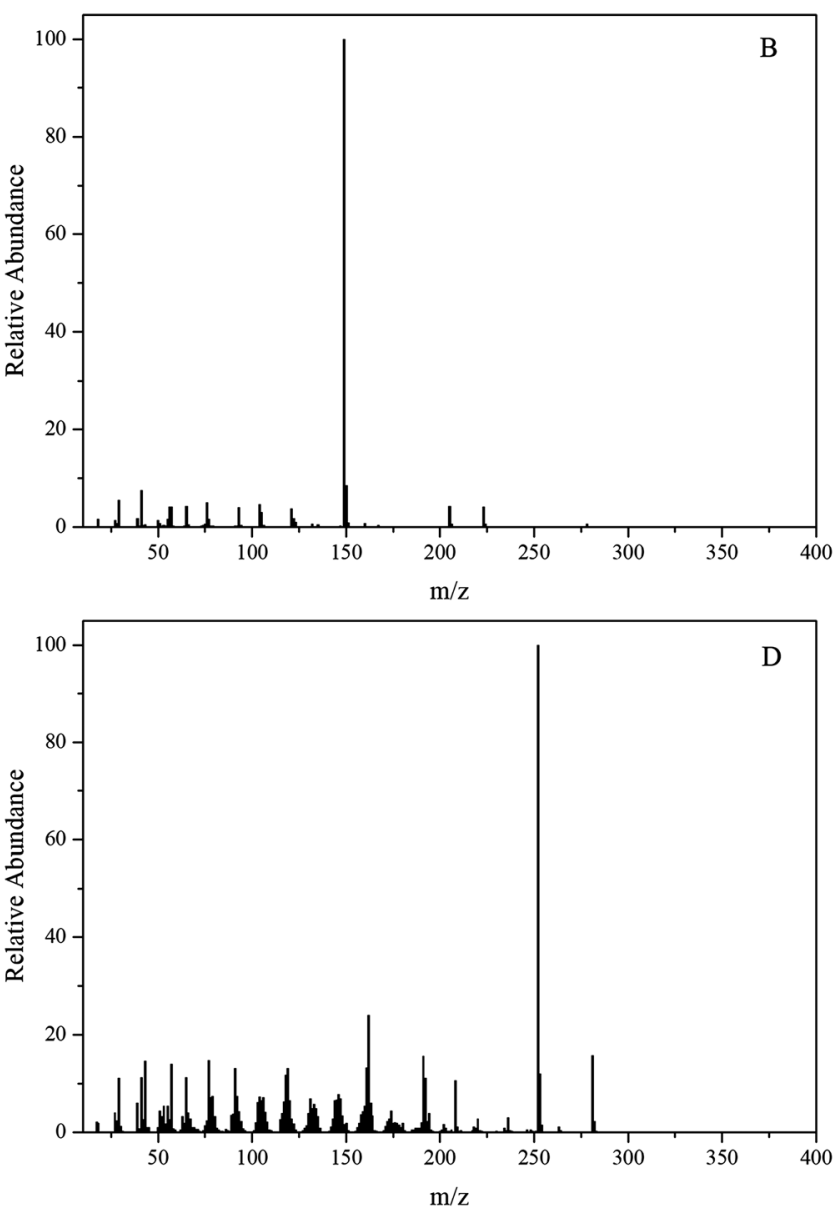

Figure 2. Mass spectra of acetochlor (A), dibutyl phthalate (B), fluorochloridone (C), and pendimethalin (D) 


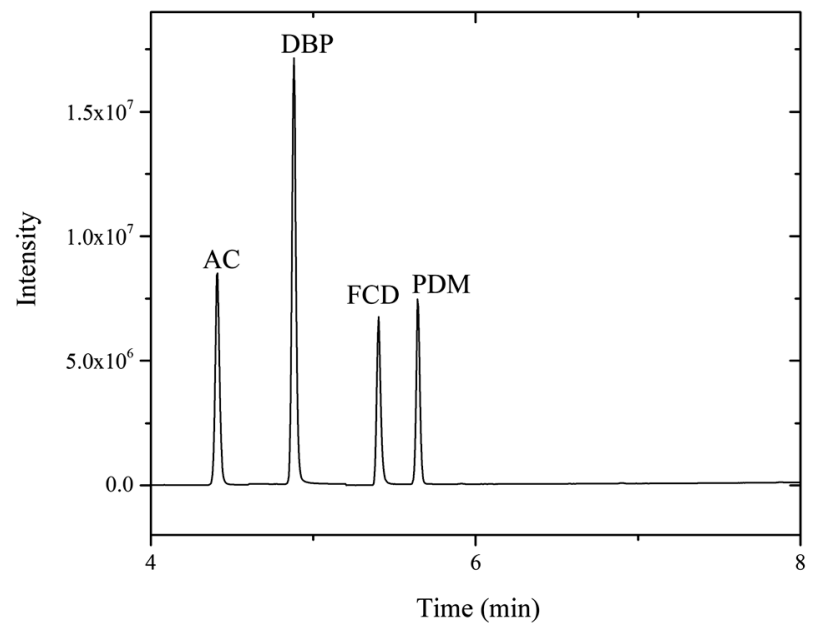

Figure 3. Typical SIM chromatogram of AC, FCD, and PDM, as well as the internal standard of DBP in a standard mixture

centered at 4.43, 5.43, 5.67, and $4.90 \mathrm{~min}$, respectively, with a retention time window of $30 \mathrm{~s}$ for extracting the main peak better.

\section{Conclusions}

For the first time, an accurate and precise GC-MS method was successfully developed and validated for simultaneous determination of acetochlor, fluorochloridone, and pendimethalin in an emerging herbicide emulsifiable concentrate formulation. To improve the accuracy and sensitivity of the method, the internal standard of dibutyl phthalate was added, and segmented selected ion monitoring mode was applied in the proposed method. Three characteristic fragment ions of each analyte was selected for SIM monitoring, and the most abundant ion was used for quantification, thus $m / z 59,149,187$, and 252 was quantitative ion for $\mathrm{AC}, \mathrm{DBP}, \mathrm{FCD}$, and $\mathrm{PDM}$, respectively. Compared with the full-scan mode, the segmented SIM function, as well as the internal standard method, improved sensibility and accuracy effectively. The fast quantification method exhibited good linearity, reproducibility, and recovery. Hence, it can be employed for routine quality control of compound herbicide containing the ternary mixtures in chemical industries.

Acknowledgements. This work was supported by the Science and Technology Project of Jiangsu Provincial Bureau of Quality and Technology Supervision (KJ168375) and the Laboratory Program of Yancheng Institute of Technology.

\section{References}

$1 \mathrm{Hu}$, J. Y.; Zhen, Z. H.; Deng, Z. B. Bull. Environ. Contam. Toxicol. 2011, 86, 95-100.

2 Shi, J. M.; Xie, C.; Liu, H. B.; Krausz, K. W; Bewley, C. A.; Zhang, S. H.; Tang, L. M.; Zhou, Z. J.; Gonzalez, F. J. Environ. Sci. Technol. 2016, 50, 9652-9660

3 Cong, C.; Wang, Z. Z.; Li, R. R.; Li, L. X.; Bu, D. X.; Wang, J. X. Weed Technol. 2014, 28, 721-728.

4 Patria, L.; Merlet, N.; Dore, M. Environ. Technol 1995, 16, 315-327.

5 Tseng, C. K.; Gless, R. D. J. Org. Chem. 1983, 48, 3564-3566.

6 Guo, W. L.; Wang, Z. Z.; Tan, J. N.; Li, W.; Wang, J. X. Nongyaoxue Xuebao 2016, 18, 605-611.

7 Wang, H. Z.; Guo, W. L.; Wang, Z. Z.; Tan, J. N.; Wang, J. X. Chin. Agric. Sci. Bull. 2016, 32, 66-70.

8 Ping, H.; Pan, L. G.; Shu, X. L.; Lu, A. X. Sens. Lett. 2011, 9, 1180 1183.

9 Yokley, R. A.; Mayer, L. C.; Huang, S. B.; Vargo, J. D. Anal. Chem. 2002, 74, 3754-3759.

10 Dagnac, T.; Jeannot, R.; Mouvet, C.; Baran, N. J. Chromatogr. A 2002, 957, 69-77.

11 Kahn, B. B.; Tomkins, D. F. J. AOAC Int. 2001, 84, 317-322.

12 Dong, Z. L.; Yang, C. G.; Xiao, S. S.; Zhao, J. H.; Li, Y. C. Fenxi Hиахие 2009, 37, 698-702.

13 Deryabina, M. A.; Yakovleva, Y. N.; Popova, V. A.; Erernin, S. A. J. Anal. Chem. 2005, 60, 80-85.

14 Tomic, Z. P.; Asanin, D.; Durovic, R.; Dordevic, A.; Makreski, P. Spectrochim. Acta, Part A 2012, 98, 47-52.

$15 \mathrm{Wu}, \mathrm{X} . \mathrm{H} . ; \mathrm{Xu}$, J.; Dong, F. S.; Liu, X. G.; Zheng, Y. Q. Anal. Methods 2013, 5, 6389-6394.

16 Dong, J.; Cao, P.; Shen, Y.; Wang, W. L.; Sun, F. C. Fenxi Huaxue 2009, 37, 417-420.

17 Galli, A.; De Souza, D.; Machado, S. A. S. Microchem. J. 2011, 98, 135-143.

18 Vankova, L.; Maixnerova, L.; Cizek, K.; Fischer, J.; Barek, J.; Navratil, T.; Yosypchuk, B. Chem. Listy 2006, 100, 1105-1110.

19 Sreedhar, M.; Damodar, J.; Venkata, N.; Jyothi, V.; Reddy, S. R. J. Bull. Chem. Soc. Jpn. 2000, 73, 2477-2480.

20 Durovic, R. D.; Dordevic, T. M.; Santric, L. R. J. AOAC Int. 2012, 95 , 1331-1337. 